\title{
«UN CONEJO DOS CONEJOS / TRES CONEJOS CON EL ALBA», LA CANCIÓN POPULAR Y EL ITINERARIO EN LOS PASOS DEL CAZADOR
}

\author{
«ONE RABBIT TWO RABBITS / THREE \\ RABBITS WITH THE DAWN», THE \\ POPULAR SONG AND THE ITINERARY \\ IN LOS PASOS DEL CAZADOR
}

\section{Margarita Freixas}

Universitat Autònoma de Barcelona

Resumen: En esta contribución se estudia la influencia de la lírica tradicional y de la canción popular en la génesis y en el desarrollo de algunos de los poemas de Los pasos del cazador (1980). Se parte del análisis del volumen como un itinerario en el que cada texto representa un hito en el camino del yo poético, un cazador que va exponiendo sus vivencias cinegéticas y amorosas a través de la reescritura de temas, géneros y motivos recurrentes en la tradición lírica española más antigua. Las versiones no publicadas de los poemas analizados son textos manuscritos y mecanografiados conservados en la Universitat Autònoma de Barcelona, en el Fondo José Agustín Goytisolo.

Palabras clave: Goytisolo; Los pasos del cazador; lírica tradicional; intertextualidad.

Aвstract: This paper studies the influence of traditional lyric poetry in the genesis and development of some of the poems in Los pasos del cazador (1980). The collection of poems is interpreted as an itinerary in which each text represents a milestone on the route of the authorial voice, a hunter who explains his hunting and love experiences through the rewriting of themes, genres and motives often used in the oldest Spanish lyrical tradition. The unpublished versions of the analyzed poems are handwritten and typewritten texts kept at the Autonomous University of Barcelona, in the Fondo José Agustín Goytisolo.

KEY WORDS: Goytisolo; Los pasos del cazador; traditional lyric poetry; intertextuality.

1 La presente investigación ha sido posible gracias a la financiación de la Generalitat de Catalunya para el Grupo de Investigación Consolidado «Grup de Lexicografia i Diacroni» (ref. 2017 SGR 1251), dirigido por Gloria Clavería. 


\section{INTRODUCCIÓN}

Los versos de la primera estrofa del poema XXXIV de Los pasos del cazador, de José Agustín Goytisolo — «Un conejo dos conejos / tres conejos con el alba: / uno queda en el sendero / los otros dos se escapaban...» (Goytisolo 1980:66)—, permiten introducir una lectura del poemario que los contiene como un cancionero centrado en el itinerario, e incidir en aspectos como la relación entre el caminante y la canción popular. El título Los pasos del cazador condensa de forma significativa el hilo conductor de los ochenta y cinco poemas que Goytisolo publica en 1980 reuniendo composiciones de gestación muy anterior, pues a comienzos de la década de los cincuenta ya había empezado a anotar «frases, historias, estribillos y cualquier tipo de expresiones» que llamaban su atención y que dieron origen a los textos que, según palabras del propio poeta, "permanecieron casi treinta años en el altillo de un armario empotrado de [su] casa de Barcelona» (Goytisolo, 1980: 17). Los textos se suceden en el volumen a partir de «una serie de secuencias o estaciones que siguen los tiempos y los pasos de un cazador durante la temporada cinegética: es decir, desde la codorniz, en agosto, hasta la veda, en marzo» (Goytisolo, 1980: 17). En los poemas los temas recurrentes son dos, «la caza y el amor. O si se prefiere, dos protagonistas insistentes: el cazador y la mujer» (Goytisolo, 1980: 18), de manera que el recorrido del yo poético es una sucesión de escenas de caza y de encuentros amorosos.

El título del poemario, Los pasos del cazador, incide en el camino y, como señala Miquel Alzueta en su reseña al volumen, pasos tiene muchas acepciones:

los pasos entendidos como actos litúrgicos; los ritos del cazador; la pasión que el cazador pone en todos sus movimientos y quietudes; el discurrir del propio cazador a través de toda la temporada de caza; el cazador como creador de un acto - el que busca la caza-, etc. (Alzueta, 1981: 63).

A los significados señalados por Alzueta podríamos añadir, citando el Diccionario de la Lengua Española de la RAE (2014 ${ }^{23}$ ), que un paso es la "distancia recorrida en cada movimiento al andar», pero también, en el lenguaje de la cinegética, el «sitio del monte por donde acostumbra pasar la caza» y un fragmento o «pasaje de 
un libro escrito».Y Riera (1991: 118) destaca también que una de las claves de interpretación de muchos de los poemas es la lectura en clave amorosa, en que la caza de amor, la conquista de la amada, se lleva a cabo "mediante una serie de "pasos necesarios"». Todas las acepciones señaladas para pasos son adecuadas para cifrar el significado del título del poemario de Goytisolo de 1980. Los ochenta y cinco poemas del volumen se ordenan para conformar un recorrido cronológico y geográfico, pero cada uno de ellos puede leerse como un paso, un texto independiente que puede desligarse del conjunto. En palabras de Goytisolo, «cada canción o cada poema es de por sí autónomo, pues posee su propio código y también distinta entidad» (Goytisolo, 1980: 18). Como subraya Jové (2005: 138), el cuidado por la forma es esencial, pues el poeta se afana por que sus poemas puedan «sobrevivir como entidades propias, capaces de ser recordados y repetidos literalmente» (Goytisolo, 1980: 16).

Y en los pasos, en los poemas de Goytisolo, la huella de la lírica tradicional y de la canción popular es profunda, tal y como han estudiado con detalle Carme Riera (1991) y Jordi Virallonga (1992). Goytisolo así lo reconoce:

Cantos en fiestas o en el trabajo, corros infantiles, nanas, charlas en bares, fondas, gasolineras, posadas y alquerías, representaban para mí un cauce fresco y hondo en el que podía aliviar la excesiva sequedad de mi castellano (Goytisolo, 1980: 12).

La canción acompaña con frecuencia el viaje del yo poético emulando las muestras de la lírica tradicional que alivia el trasiego de quien camina o de quien trabaja. Los versos «Un conejo dos conejos / tres conejos con el alba...», evocados al inicio de esta contribución, recuerdan otras canciones antiguas de una tradición tan asentada que incluso se arraiga en la lexicografia. Los primeros diccionarios monolingües en español recogen el refrán cantar las tres ánades, que recuerda unos versos con una función similar a los de Goytisolo, dedicados a alegrar el camino, «tres ánades madre, pasan por aquí, mal penan a mí». El Diccionario de Autoridades (1726), haciéndose eco de Sebastián de Covarrubias (1611), recoge bajo la voz ánade la costumbre de amenizar el camino con la canción ${ }^{2}$ :

2 Como señala Frenk (2006 [1961]: 543), los diccionarios muestran en este caso "que no se proverbializa el cantar mismo, sino el hecho de cantarlo». Frenk 
Cantar las tres ánades Madre. Phrase con que se explica que alguno vá caminando alegremente, y sin sentir el trabájo. Covarr. dice vino de cierta coplilla antígua y vulgar, que dice:

\author{
Tres ánades Madre \\ passan por aqui \\ mal penan a mi.
}

Lat. Cantillare ludricam cantiunculam. CERV. Nov. 8. fol. 235. Se llegó desde Zahára à Valladolid cantando las tres ánades Madre. QUEVED. Cuent.Y que quisiesse que no quisiesse se iría con él al cabo del mundo cantando las tres ánades Madre.

Figura 1. Real Academia Española (1726-1739), Diccionario de Autoridades, s. v. ánade.

En las páginas siguientes se estudiará la relación que Goytisolo (1980) establece entre el tema del camino y la canción popular en Los pasos del cazador a través del análisis de distintas versiones de los poemas que conforman este volumen y que, como confesó su propio autor, fueron fruto de una revisión muy profunda. Gracias al Fondo José Agustín Goytisolo, custodiado en la Biblioteca de Humanidades de la Universitat Autònoma de Barcelona, es posible conocer algunos textos manuscritos y mecanografiados que contienen versiones y correcciones de distintas composiciones finalmente incluidas en Los pasos del cazador. El análisis de la reescritura de estos poemas permite descubrir cómo en el proceso de conformación del volumen se afianzan los temas y motivos de esta obra.

\title{
2. LOS HITOS EN EL CAMINO
}

El primer texto del poemario, unos versos de GilVicente que José Agustín Goytisolo incluye como elemento liminar del poemario — «a caza de amor / es de altanería / trabajos de día / de noche dolor»-, introduce el tema de la caza de amor como un elemento central de la obra. De este modo, entronca el poemario con la tradición de raíces medievales de la cacería de amor, en la que el

(2003: 162-164) reúne numerosos pasajes de textos literarios en los que personajes en camino cantan la coplilla «Las tres anádes» o su variante «Dos ánades, madre». 
amado-cazador se identifica con el halcón que encalza a su presa, la amada, la "gaza guerrera» en los versos de GilVicente ${ }^{3}$.

Tras esta evocación, se sucederán los pasos, los poemas, del cazador que caza y es cazado. El poema I de Los pasos del cazador señala el inicio del camino emprendido por el yo poético. Las correcciones que Goytisolo realiza en el texto intensifican la invitación a la caza en la tercera y última estrofa:

\section{I [versión A manuscrita]}

PARA AQUELLOS MONTES

TE INVITO A SUBIR BROTA SIEMPRE EL AGUA CORRE DESDE ABRIL.

Y PALOMAS MIL.

\section{I [versión B mecanografiada} con correcciones manuscritas] $[\ldots]$

Por aquellos montes

te invito a subir se abrió ya la veda atrás quedó Abril.

Y palomas mil.

\section{I [versión impresa]}

$[\ldots]$

Por aquellos montes

yo te invito a ir: tú irás por la caza y yo iré por ti.

Y palomas mil.

(Goytisolo, 1980: 31)

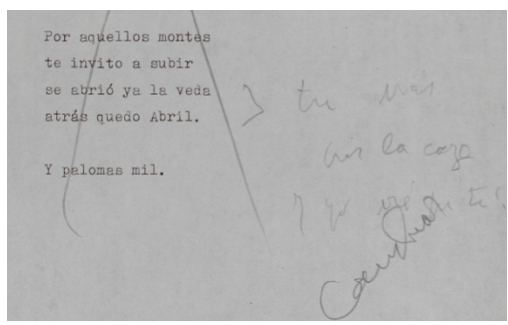

Versiones conservadas en el Fondo José Agustín Goytisolo (UAB, Biblioteca de Humanidades) ${ }^{4}$

Figura 2.Versiones del poema I de Los pasos del cazador.

3 Para una reseña de las recreaciones del tema de la cacería de amor en la literatura española, véanse Alonso (1947) y López Castro (2000).

4 La versión A se conserva bajo el topográfico Goy_0113 en el Fondo José Agustín Goytisolo de la Universitat Autònoma de Barcelona, depositado en la Biblioteca de Humanidades. La versión B se encuentra en el conjunto de 26 folios con poemas 
Como se muestra en la tabla anterior (Figura 2), la primera versión manuscrita del poema terminaba con los mismos versos de la primera estrofa, «brota siempre el agua / corre desde abril $»^{5}$; repetición que se suprime en la segunda versión mecanografiada, cuyos versos finales inciden en el tiempo de la acción, cuando pasada la primavera («atrás quedó Abril») se levanta la veda. La corrección en lápiz con la indicación "Cambiar» contiene la versión definitiva de los últimos versos de la estrofa, «tu irás por la caza / y yo iré a por ti», que introducen de forma más clara el motivo de la caza de amor: quien acude al monte por la caza es cazado, pues, como ya se advertía en la segunda estrofa, «Por aquellos montes / llenos de color / y sobre sus prados / bueno es el amor». A partir de esta invitación, el poemario puede leerse, en palabras de Fanny Rubio (1980), como «un diario de cazador, en verso, siempre atento a la presa, al camino y al conducto folklórico y lingüístico». La caza es tratada tanto en un sentido literal como metafórico. Las técnicas de la cinegética real están muy presentes en el poemario, en el que se reivindican las prácticas consideradas más nobles y se llega a afear el comportamiento de los furtivos (poema XXX) y de los que cazan al ojeo (poema XXIII). La caza en su sentido metafórico ofrece la posibilidad de dar una doble lectura a poemas como el LXI:

Se aparta del bando
atrasa su vuelo:
y de pronto se alza
buscando aire nuevo.
Va herida de muerte
y remonta el cielo:
caerá esa perdiz
como un trapo viejo.

A su alta agonía

la torre pusieron:

corregidos de Los pasos del cazador bajo el topográfico Goy_0176. En el mismo fondo se encuentra otra versión mecanografiada del texto (topográfico Goy_0243), sin anotaciones manuscritas, que coincide con la impresa en el poemario de Goytisolo, salvo por el hecho de que está encabezada por un título, "Y PALOMAS MIL», que finalmente no se incluyó en el volumen editado por Lumen.

5 Las referencias al agua y al río como lugares propicios para el amor son constantes en el libro y aparecen en la primera estrofa del primer poema y en los poemas XI, XXI y LXXIX. 
quien la vio una vez, no la olvida luego.

En los versos citados, Goytisolo emplea el lenguaje especializado de la cinegética, hacer la torre a la perdiz, que bien puede referirse tanto al ave que remonta el vuelo antes de caer desplomada sin vida como a la amante que cae rendida tras haberse resistido. En otras ocasiones, la referencia a la caza de amor es directa, como en el poema XXIV, en que el miedo de la amada se equipara al de la avutarda: «Solo quería / charlar contigo / pero te escapas. / Tienes más miedo / que una avutarda».

Los hitos en el camino del cazador son los poemas que conforman el volumen y que se suceden encabezados por una numeración en romanos, del I al LXXXV, que organiza los textos en una secuencia ordenada, prescindiendo de los títulos que aparecen en algunas de las versiones de los poemas conservadas en el Fondo José Agustín Goytisolo (s. f.) y que se recogen en la tabla siguiente:

\begin{tabular}{lcr}
$\begin{array}{l}\text { Títulos de los poemas } \\
\text { en los textos manuscritos }\end{array}$ & $\begin{array}{c}\text { Topográfico en } \\
\text { el Fondo } \\
\text { José A. Goytisolo } \\
\text { (s. f.) }\end{array}$ & $\begin{array}{r}\text { Número del poema } \\
\text { en Goytisolo (1980) }\end{array}$ \\
\hline Y palomas mil & $\begin{array}{l}\text { Goy_0113 } \\
\text { Goy_0243 }\end{array}$ & I \\
\hline Paseando en veda & Goy_0783 & II \\
\hline Voló ya el pájaro & Goy_0224 & III \\
\hline Calor & Goy_1100 & IV \\
\hline La codorniz en agosto & Goy_0951 & V \\
\hline La embustera & Goy_0295 & VI \\
\hline En el Adaja & Goy_0112 & VIII \\
\hline Arrorró & Goy_1101 & X \\
\hline Canción de amigo & Goy_0137 & XI \\
\hline Las torcaces & Goy_0291 & XII \\
\hline
\end{tabular}

- En el manuscrito, el título «Calor» aparece como corrección al título tachado «Otoño caliente». 


\begin{tabular}{|c|c|c|}
\hline $\begin{array}{l}\text { No todas las uvas } \\
\text { Racimo temprano }\end{array}$ & $\begin{array}{l}\text { Goy_0289 } \\
\text { Goy_1187 }\end{array}$ & XIV \\
\hline Van y vuelan & Goy_0130 & XV \\
\hline Plomo en las alas & Goy_0111 & XVI \\
\hline Una turista en Trujillo & Goy_0974 & XVII \\
\hline El viento murmurador & Goy_0135 & XVIII \\
\hline De las patirrojas & Goy_0107 & XIX \\
\hline Ferias de Trujillo & Goy_0149 & $\mathrm{XX}$ \\
\hline Sin nombre ${ }^{7}$ & Goy_0105 & XXI \\
\hline Se van & Goy_0836 & XXII \\
\hline Que no al ojeo & Goy_0298 & XXIII \\
\hline Más que una avutarda & Goy_0293 & XXIV \\
\hline A Guadalupe & Goy_0471 & XXV \\
\hline La lechuza llora & Goy_1064 & XXVI \\
\hline No un juego & Goy_0892 & XXVII \\
\hline La envidiada & Goy_0131 & XXVIII \\
\hline La cabra & Goy_1094 & XXIX \\
\hline Furtivo & Goy_0103 & $\mathrm{XXX}$ \\
\hline El pájaro bobo & Goy_0218 & XXXI \\
\hline Arroyo de la luz & Goy_1095 & XXXII \\
\hline En la Sierra de Gata & Goy_0144 & XXXIV \\
\hline Nana mi perra ea & Goy_0732 & XXXV \\
\hline Casada pechos hermosos & Goy_0117 & XXXVI \\
\hline En el río de Coria & Goy_1039 & XXXVII \\
\hline No vive viva & Goy_0116 & XXXVIII \\
\hline Bajará la nieve & Goy_1097 & XXXIX \\
\hline Pásame la frontera & $\begin{array}{l}\text { Goy_0124 } \\
\text { Goy_0125 }\end{array}$ & XL \\
\hline A la pata coja & Goy_0223 & XLI \\
\hline
\end{tabular}

$\overline{7}$ Este título, «Sin nombre», está escrito encima de un título tachado: «Entonces». 


\begin{tabular}{|c|c|c|}
\hline Ahora duerme & Goy_0104 & XLII \\
\hline Sisones & Goy_0147 & XLIII \\
\hline A Portugal no & Goy_1098 & XLV \\
\hline Sorpresa en Las Villuercas & Goy_1096 & XLVII \\
\hline Cambiar de oficio & Goy_0132 & XLVIII \\
\hline El zorro viejo & Goy_0108 & XLIX \\
\hline Posada en Almendralejo & Goy_0127 & $\mathrm{L}$ \\
\hline Canción de la reina mora ${ }^{8}$ & Goy_0122 & LI \\
\hline Lo mejor estaba allí & Goy_0139 & LII \\
\hline Mala niebla & Goy_0143 & LIII \\
\hline Fea bonita fea & Goy_1083 & LIV \\
\hline Este año ${ }^{9}$ & Goy_0380 & LV \\
\hline Invitado & Goy_1086 & LVI \\
\hline Donde el aire acaba & Goy_0296 & LIX \\
\hline Capote ovejero & Goy_0123 & LX \\
\hline No viene & Goy_0118 & LXII \\
\hline Don Benito & Goy_0861 & LXIII \\
\hline En lo negro negro & Goy_0297 & LXIV \\
\hline La enlutada & Goy_0860 & LXV \\
\hline $\begin{array}{l}\text { Gasolinera bajo Sierra Mo- } \\
\text { rena }\end{array}$ & Goy_0142 & LXVI \\
\hline La señora liebre & Goy_0379 & LXVII \\
\hline Hay mus & Goy_0979 & LXVIII \\
\hline Canción en Malpartida & Goy_0109 & LXIX \\
\hline $\begin{array}{l}\text { Estación de servicio en Pla- } \\
\text { sencia }\end{array}$ & Goy_0145 & LXX \\
\hline
\end{tabular}

La parte final del título, "Canción de la siega-hierba", aparece tachada y con la corrección «reina mora». En todo el texto se sustituyen las referencias a la «siega-hierba» por «reina mora», lo que acerca la composición a los motivos de la lírica tradicional.

9 El manuscrito tiene dos títulos tachados: «Los conejos no es» $\mathrm{y}$ «Los conejos cuidado», antes del título sin tachar: «Este año». 


\begin{tabular}{llr}
\hline Patos azulones & Goy_0941 & LXXI \\
\hline La manta & Goy_0119 & LXXIII \\
\hline Al tren al tren & Goy_0294 & LXXIV \\
\hline Embalse de ElVicario & Goy_0129 & LXXV \\
\hline La Chana & Goy_0138 & LXXVI \\
\hline Carnaval & Goy_0222 & LXXVII \\
\hline Al río & Goy_0115 & LXXIX \\
\hline Pronto el cierre & Goy_0146 & LXXX \\
\hline La prima & Goy_0148 & LXXXII \\
\hline El torrente & Goy_0828 & LXXXIII \\
\hline Al trébol rojo & Goy_0246 & LXXXIV \\
Al trébol & Goy_1102 & LXXXV \\
\hline Corre corre corre & Goy_0221 & \\
\hline Al fin del invierno & Goy_0114 &
\end{tabular}

Los títulos de los poemas que finalmente Goytisolo optó por no incluir en el volumen impreso se refieren en su mayoría al tipo de caza y/o a las referencias espacio-temporales que permiten situar las experiencias narradas: La codorniz en agosto (V), En el Adaja (VIII), Las torcaces (XII), Una turista en Trujillo (XVII), De las patirrojas (XIX), Ferias de Trujillo (XX), A Guadalupe (XXV), Arroyo de la luz (XXXII), En la Sierra de Gata (XXXIV), En el río de Coria (XXXVII), A Portugal no (XLV), Sorpresa en Las Villuercas (XLVII), Posada en Almendralejo (L), Gasolinera bajo Sierra Morena (LXVI), Canción en Malpartida (LXIX), Estación de servicio en Plasencia (LXX), Embalse de El Vicario (LXXV), Al fin del invierno (LXXXV) ${ }^{10}$.

En pos de la caza, se traza en el poemario un recorrido geográfico por las regiones de Castilla La Mancha, Extremadura y Castilla

10 Además de los poemas recogidos en la tabla, el Fondo José Agustín Goytisolo conserva algunas versiones de composiciones que no se encabezan mediante ningún título y que finalmente se incluyeron dentro del volumen Los pasos del cazador. Se trata de los siguientes poemas: [Yo canto / entre los olivos...] (signatura Goy_0100, poema IX); [El día de San Antonio...] (signatura Goy_0099, poema XLIV); [Esas noches en que duermo / tan sola mi robador (halagador)...] (signatura Goy_0102, poema LVIII); y [Explícate ya / si andas medio cojo...] (signatura Goy_0101, poema LXXII). 
y León. De dichos lugares se citan pueblos, ciudades y parajes de manera que el recorrido da comienzo en Castilla La Mancha:

Almadén (IX), Almodóvar del Campo (XII).

Sigue por Extremadura:

Trujillo (XVII y XX), Guadalupe (XXV).

Continúa por Castilla y León:

Ciudad Rodrigo (XXIX), en tierras de Salamanca (XXX) ${ }^{11}$.

Vuelve a Extremadura:

Arroyo de la Luz (XXXII), Sierra de Gata (XXXIV), Coria (XXXVII), Cáceres (XLII), Malpartida (XLIV), frontera con Portugal (XLV), Almendralejo (L), Madrigalejo (LVI).

Y termina en Castilla y León:

Puerto de Tornavacas-Ávila (LXX) y, de nuevo, Ciudad Rodrigo (LXXXIII).

Los títulos de las versiones manuscritas de los poemas también aportan topónimos que muestran la relación de los textos con parajes visitados por el poeta. En los casos siguientes, los nombres de ríos, comarcas, accidentes geográficos o pueblos se ocultan al lector al suprimirse los epígrafes, ya que no forman parte de los versos del texto: En el Adaja (versión del poemaVIII, signatura Goy_0112), Sorpresa en Las Villuercas (versión del poema XLVII, signatura Goy_1096), Posada en Almendralejo (versión del poema L, signatura Goy_0127), Gasolinera bajo Sierra Morena (versión del poema LXVI, signatura Goy_0142), Estación de servicio en Plasencia (versión del poema LXX, Goy_0145), Embalse de El Vicario (versión del poema LXXV, signatura Goy_0129).

Tal y como confiesa el propio Goytisolo (1980: 12) en el prólogo a Los pasos del cazador, las ubicaciones presentes en los poemas son lugares que él mismo recorrió en sus experiencias de caza de

11 Véase García Mateos (1983) sobre la presencia de las tierras salmantinas en Los pasos del cazador. 
su época de estudiante universitario en Madrid, «a finales de los cuarenta y principios de los cincuenta» (Cotoner, 2010: 150):

Así puedo decir que he pateado buena parte de las provincias de Cáceres y Badajoz; de Toledo, desde Talavera hacia el oeste; y de Ciudad Real, de Manzanares para allá, con incursiones a varias comarcas y pueblos de las provincias limítrofes de Ávila y Salamanca (Goytisolo, 1980: 12).

Los poemas de Los pasos del cazador contienen también referencias temporales que permiten situar el itinerario del yo poético en un arco temporal que va de agosto («mediando ya agosto», poema V) a marzo-principios de abril («sale Marzo y llega Abril», poema LXXXIV), temporada en la que el cazador recorre parajes naturales, sierras, montes y ríos, pueblos y posadas, y en ellos se dedica a la actividad cinegética y al solaz amoroso.

Los encuentros con serranas, malcasadas y amigas conforman un cancionero en el que se va combinando la voz del cazador que se dirige a la amada y la voz de la mujer que solicita al cazador. Según Riera (1991: 118), la presencia de la mujer se encuentra en casi la mitad del poemario, en treinta y seis de sus ochenta y cinco poemas. En algunas de estas composiciones, el aprovechamiento de un aspecto propio de la lírica tradicional, la voz poética de la mujer que se dirige al amado (poemas XXXIII, LVIII, LX, LXII, LXVI, LXIX, LXXIV), es empleado por Goytisolo como un recurso para presentar la libertad con que la mujer es retratada por el poeta y que se entrega al amado con «desenvoltura y espontaneidad» (en palabras del propio escritor en el prólogo a Los pasos del cazador [Goytisolo, 1980:27]) o que toma la iniciativa (Cotoner, 2010: 149 y ss.). De los modelos de mujer de la lírica tradicional, Goytisolo recrea los que le permiten mostrar "una relación de igual a igual» (Roda Bruce, 1999: 233) y omite personajes ingenuos como el de la muchacha que confiesa su amor a la madre (Roda Bruce,1999:234) o el de la niña que no quiere ser monja (Roda Bruce, 1999: 236).

El cancionero publicado en su forma definitiva es el resultado de la organización en una secuencia temporal y espacial de «un artificioso y ordenado conjunto de poemas y canciones» (Goytisolo, 1980: 17), tras espigar y reescribir los textos a partir de materiales preliminares: 
Aunque reescritos, corregidos varias veces, seleccionados al fin y ordenados en fecha reciente, los poemas y canciones de este libro son, en buena parte, el resultado de notas, esbozos de poemas, recuerdos y fantasías de mis primeros años de cazador (Goytisolo, 1980: 11).

El Fondo José Agustín Goytisolo de la Biblioteca de Humanidades de la Universitat Autònoma de Barcelona conserva versiones de temática afin a Los pasos del cazador y que podrían haberse descartado en la selección final. Se trata de las referencias siguientes:

\begin{tabular}{ll}
\hline$[\text { Entra una luz ... }]^{12}$ & Goy_0098 \\
\hline El forastero & Goy_0106 \\
\hline Mira el mochuelo & Goy_0110 \\
\hline Toda la noche & Goy_0120 \\
\hline Estrella de tierra y mar & Goy_0121 \\
\hline Romancillo de la perra serrana ${ }^{13}$ & Goy_0126 \\
\hline Cara de luna & Goy_0128 \\
\hline El retornado a Coria & Goy_0133 \\
\hline El enfadado & Goy_0134 \\
\hline Romero amiga & Goy_0136 \\
\hline Reír de risa & Goy_0140 \\
\hline La manzana & Goy_0141 \\
\hline
\end{tabular}

Las versiones de poemas no incluidos tratan temas y motivos semejantes a los publicados en Los pasos del cazador: el cazador que se separa de la amada al alba («Entra una luz...») o al proseguir su camino («El retornado a Coria»); la amada que se entrega al cazador-forastero («El forastero»); el encuentro amoroso en la noche («Toda la noche») o en un romeral («Romero amiga»); el halago a la

12 En este caso el poema no va encabezado por un título y en la referencia bibliográfica se identifica mediante el primer verso: «Entra una luz...».

13 En el manuscrito, el poema, finalmente no incluido en Los pasos del cazador, se titula "Romancillo de la eierva serrana», con la palabra "cierva» tachada y sustituida por "perra», a la que Goytisolo dedica una nana en el poema XXXV. 
amada morena («Estrella de tierra y mar» $\left.{ }^{14}\right)$, a la muchacha con cara de luna ("Cara de luna») o a la mujer liberada y burlona («Reír de risa»); la apelación a los animales que acompañan al cazador, como el mochuelo que observa en la noche («Mira el mochuelo» ${ }^{15}$ ) o la perra que lo acompaña ("Romancillo de la perra serrana» ${ }^{16}$ ); y la metáfora del fruto arrancado para simbolizar la mujer maltratada por otros («La manzana $\left.»^{17}\right)^{18}$.

Estas versiones descartadas muestran, en definitiva, el proceso de criba del material poético escrito con anterioridad, que supone no solo la reescritura de los textos, sino también la selección de los materiales que finalmente conformaron Los pasos del cazador.

\section{LA LÍRICA TRADICIONAL Y LA CANCIÓN POPULAR EN EL ITINERARIO}

Los poemas de Los pasos del cazador y sus fuentes en la lírica tradicional y en la canción popular han sido ampliamente estudiados por Carme Riera (1991) y por Jordi Virallonga (1992), pero están aún

14 Los requiebros a la mujer morena son también el tema central del poema LIV de Los pasos del cazador, mientras en el LI es la propia mujer morena quien reivindica su condición.

15 En Los pasos del cazador, el poema dedicado a la lechuza (XXVI) tiene una expresividad lírica de la que carece este texto, en que únicamente se ensalza el ave rapaz como símbolo de la sabiduría, mientras que en el poema publicado, el «grito en la sombra" de la lechuza "semeja el llanto de un niño / que se olvidaron en la alcoba», en un recuerdo del poeta por la madre a la que perdió (Roda Bruce: 1999: 241).

16 Este poema presenta un complejo proceso de reescritura, pues la «perra caprichosa» a la que dedica el título del texto, «Romancillo a la perra serrana», sustituye a la "cierva graciosa» que aparece tachada y que habría permitido una lectura amorosa del texto, propiciada por la ubicación en el río donde se encuentra el poeta lavando su ropa. En Los pasos del cazador los requiebros a la perra, compañera de viaje, aparecen en poemas como el II y el XXXV, una nana a la perra "perdiguera». El tema de los encuentros amorosos en el río se encuentra de forma recurrente (véase la nota 5 de la presente contribución).

17 Véase en Los pasos del cazador, en el poema XIV, la identificación de la mujer con un racimo temprano de uvas que puede evitar ser devorada por el amo.

18 De temática más apartada a los poemas de Los pasos del cazador es «El enfadado» (Goy_0134), en el que el poeta reniega del trato recibido por parte del padre de la amada. No obstante, las referencias al entorno rural, pues el enfado se produce "por siete sacos de almendras / y una carga de aceitunas», están en consonancia con la ambientación de este poemario. 
por analizar las variantes que presentan en las versiones manuscritas y mecanografiadas previas a su impresión y que se conservan en el Fondo José Agustín Goytisolo de la Biblioteca de Humanidades de la Universitat Autònoma de Barcelona. Como podrá comprobarse en esta primera aproximación, el análisis de los cambios que el poeta realiza en los textos ofrece datos interesantes sobre la impronta de la tradición literaria en la génesis y en la evolución de las composiciones de Los pasos del cazador. Examinaré, en concreto, las transformaciones que sufren tres poemas, el XXXVI, el XXXI y el LXXIII, elegidos porque ejemplifican el empleo de materiales de la tradición lírica muy distintos: desde la lírica tradicional, con el eco de las canciones de las malmaridadas, en el poema XXXVI; a la canción popular, con la evocación de una canción infantil de tono burlesco, en el XXXI; pasando por el baile, con la alusión al género de la barcarola, en el LXXIII.

Carme Riera y Ramón García Mateos (Goytisolo, 2011²: 16) explican de forma muy gráfica la continua reescritura que José Agustín Goytisolo llevaba a cabo en sus textos:

José Agustín Goytisolo entendía su obra como una especie de palimpsesto, de ahí que borrara y reescribiera sobre lo borrado y a veces, no contento con lo nuevamente escrito, volviera tras las huellas de lo eliminado y acabara por desechar lo corregido.

La voluntad de ofrecer un abanico amplio de escenas y de posibilidades líricas podría explicar, como mostraré a continuación, algunos de los cambios profundos que se producen en determinados poemas de Los pasos del cazador. Comenzaré el análisis por un texto, el poema XXXVI, que muestra la evolución de una composición de Goytisolo a partir de un motivo relacionado con la lírica tradicional que finalmente se desdibuja en la versión definitiva del poema. Se trata de un poema cuya versión manuscrita presenta numerosas correcciones. En la tabla siguiente se recoge, en la columna izquierda, la transcripción de la versión manuscrita por Goytisolo con las correcciones que muestran un proceso de escritura inacabado: 


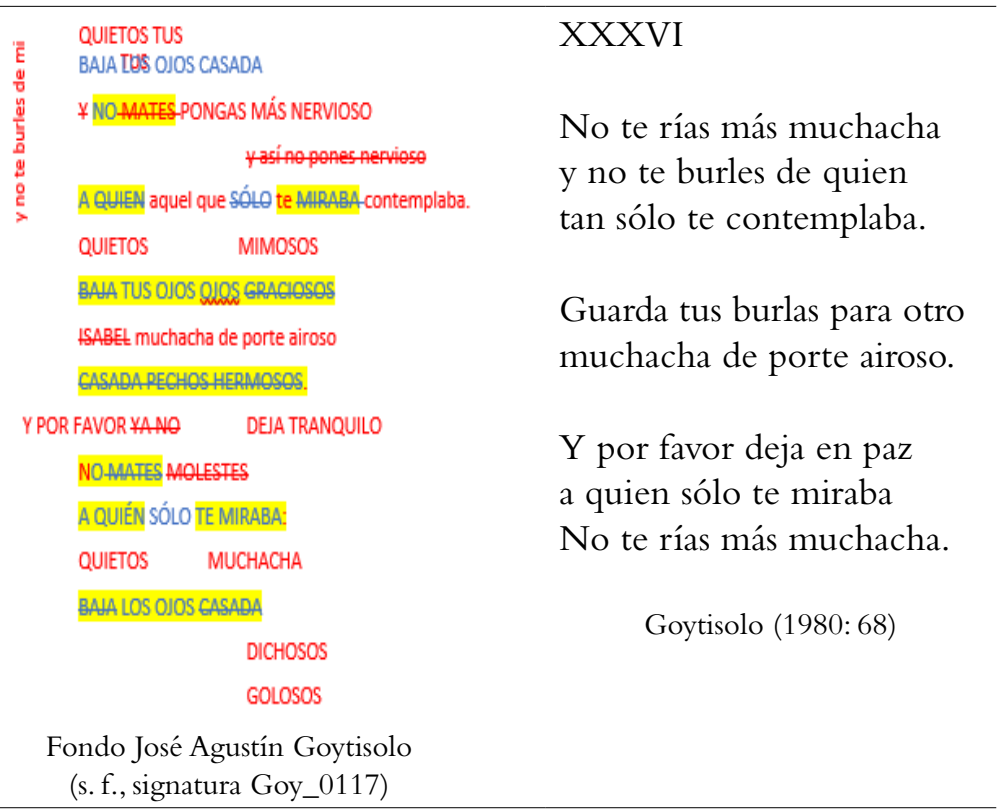

Figura 3.Versión manuscrita ${ }^{19}$ y versión impresa del poema XXXVI de Los pasos del cazador.

En las versiones anteriores al poema que definitivamente se imprime en Los pasos del cazador (columna izquierda de la Figura 3), José Agustín Goytisolo remedaba un romance muy conocido de La malmaridada, tan recreado y tan glosado en la tradición lírica española que en la versión del Cancionero de Amberes (1557) se encuentra incluso un lamento por haber sido no solo mal casada sino también «mal trovada / de los poetas tratada / peor que de tu marido»:
¡Oh bella malmaridada
Abaja los ojos casada, y a qué manos has venido: no mates a quien te miraba.
mal casada y mal trovada, de los poetas tratatada Casada, pechos hermosos, peor que de tu marido! abaja tus ojos graciosos. No mates a quien te miraba: abaja los ojos, casada.
(Canción de la malmaridada, versión del Cancionero de Amberes, 1557, recogida en Torner, 1966: 281-285).

19 En la imagen de la Figura 3 se ha intentado transcribir de la forma más clara posible el manuscrito con tinta de dos colores de José Agustín Goytisolo, que empleó el azul para la primera versión y el rojo para las tachaduras y correcciones. La imagen del manuscrito puede consultarse por internet gracias a la digitalización del Fondo José Agustín Goytisolo: https://ddd.uab.cat/record/94448. 
Si se comparan las notas manuscritas de Goytisolo con los versos marcados en cursiva de la canción de la malmaridada, puede comprobarse cómo el poeta cita de forma literal pasajes de la composición tradicional que está en la base de este poema sobre la amada que desprecia a quien la contempla. Aún más relaciones pueden establecerse con otros textos, si nos fijamos en el nombre propio, «Isabel», que aparece tachado en el manuscrito de Goytisolo, y en el motivo de la risa. Estos dos elementos se incorporan en un poema manuscrito que el poeta finalmente no incluyó en Los pasos del cazador. Se trata del texto "Reír de risa», que el Fondo José Agustín Goytisolo (s.f.) atesora bajo la signatura «Goy_0140»y en el que la reescritura no parte de la canción de la malmaridada, sino de una letrilla romanceada muy conocida (véase Frenk, 2003:1619) gracias a un poema de Luis de Góngora:

\begin{tabular}{|c|c|c|}
\hline 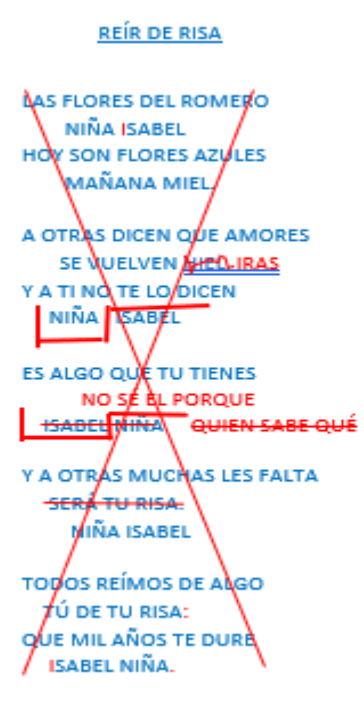 & $\begin{array}{l}\text { Las flores del romero, } \\
\text { niña Isabel, } \\
\text { hoy son flores azules, } \\
\text { mañana serán miel. } \\
\text { Celosa estás, la niña, } \\
\text { celosa estás de aquél, } \\
\text { dichoso, pues le buscas, } \\
\text { ciego, pues no te ve. } \\
\text { Ingrato, pues te enoja, } \\
\text { y confiado, pues } \\
\text { no se disculpa hoy } \\
\text { de lo que hizo ayer. } \\
\text { Enjuguen esperanzas } \\
\text { lo que lloras por él, } \\
\text { que celos entre aquéllos } \\
\text { que se han querido bien, } \\
\text { hoy son flores azules, } \\
\text { mañana serán miel. }\end{array}$ & $\begin{array}{l}\text { Aurora de ti misma, } \\
\text { que, cuando a amanecer } \\
\text { a tu placer empiezas, } \\
\text { te eclipsan tu placer; } \\
\text { serénense tus ojos, } \\
\text { y más perlas no des, } \\
\text { porque al sol le está mal } \\
\text { lo que a la aurora bien. } \\
\text { Desata como nieblas } \\
\text { todo lo que no ves, } \\
\text { que sospechas de amantes } \\
\text { y querellas después, } \\
\text { hoy son flores azules, } \\
\text { mañana serán miel. }\end{array}$ \\
\hline
\end{tabular}

Figura 4. Poema manuscrito del Fondo José Agustín Goytisolo (s.f.: signatura Goy_0140) y poema de Luis de Góngora (2000 [1608]: 436-437).

A pesar de que el poema de Goytisolo transcrito en la Figura 4 no fue finalmente elegido para formar parte del volumen, pudo inspirar la reescritura del poema XXXVI, donde el motivo de la malcasada o la malquerida queda desplazado por la importancia que cobra la risa de la amada, aspecto central de la composición descartada «Reír de risa». En la decisión de no aprovechar en el poema XXXVI ni las referencias intertextuales a la canción de la malmaridada ni ninguna alusión al estribillo recogido en el poema de Luis de Góngora — «Las flores del romero, / niña Isabel, / hoy 
son flores azules, / mañana serán miel»— pudo influir el hecho de que Jaime Gil de Biedma ya había aunado en una misma composición referencias a ambos textos. En el poemario Moralidades, los versos de "A una dama muy joven, separada» se construyen a partir de referencias a textos poéticos de muy distintas épocas, que van desde la lírica tradicional ${ }^{20}$, incluyendo el recuerdo de la «Canción del pirata» de José de Espronceda — «Hoy vestida de corsario / en los bares se te ve / con seis amantes por banda»- y la evocación de un bolero popular en la juventud de Gil de Biedma, con la denominación de la mujer como «niña Isabel», en recuerdo al estribillo siguiente: «Niña Isabel, ten cuidado, / donde hay pasión hay pecado. / Niña Isabel, en amores / lo más fácil es que llores» (Voutsa 2012: 239):

A UNA DAMA MUY JOVEN, SEPARADA

En un año que has estado casada, pechos hermosos, amargas encontraste las flores del matrimonio.

Y una buena mañana la dulce libertad elegiste impaciente, como un escolar.

Hoy vestida de corsario en los bares se te ve con seis amantes por banda -Isabel, niña Isabel$[\ldots]$

Jaime Gil de Biedma, Moralidades (1966).

La reescritura del poema XXXVI de Los pasos del cazador aparta el texto del recuerdo de los versos de la malmaridada, tema que,

20 Uno de los recursos más recurrentes en la poesía de Gil de Biedma es la intertextualidad. En cuanto a las relaciones de Goytisolo con Gil de Biedma y el grupo de escritores de la denominada Escuela de Barcelona, a la que ambos pertenecen, véase Riera (1988: 70). Gil de Biedma expresó su deuda con la lírica medieval en una conferencia en 1984 en Trieste, «La imitación como mediación, o de mi Edad Media», publicada en 1985. 
como Jaime Gil de Biedma, José Agustín Goytisolo tratará desde un punto de vista moderno en otro poemario, A veces gran amor (1981), en el texto «Escoger la libertad», dedicado a los matrimonios fallidos durante el franquismo. No obstante, el tema de la dama malcontenta con su amante es un motivo recurrente en Los pasos del cazador, donde se pueden encontrar otros reflejos de la dama malquerida, como en el poema que dedica a la Chana (LXXVI):

No sé qué te pasa

tienes mal talante

¿o serán los tratos

que te da tu amante?
¡Ay Chana

cuánto te gustan

las avellanas!

$[\ldots]$

La nueva versión del poema XXXVI permitía además a José Agustín Goytisolo introducir un tema también muy común en la lírica popular: las burlas de la amada a su amante (Roda Bruce, 1999: 238). A este tema de las burlas se dedica otro de los poemas de Los pasos del cazador, el XXXI, la canción del pájaro bobo y la golondrina, que mostraremos a continuación como un ejemplo de texto elaborado a partir de una canción de corro infantil. El carácter lúdico de muchos de los poemas ha sido interpretado por Roda Bruce (1999: 237) en relación

con el hecho de que el paraíso del cazador es, en cierto modo, un retorno a la infancia.Tanto las 'niñas' de la lírica tradicional como el cazador, conservan un carácter juvenil y juguetón. Muchas canciones tienen un tono marcadamente infantil.

Como puede comprobarse en la imagen siguiente, la versión manuscrita del texto, «El pájaro bobo», lleva por título una alusión a una canción popular cuyas referencias, a diferencia de lo que ocurre en el poema XXXVI, se mantienen en la versión definitiva, de manera que el lector que es capaz de identificarlas puede comprender mejor el poema: 


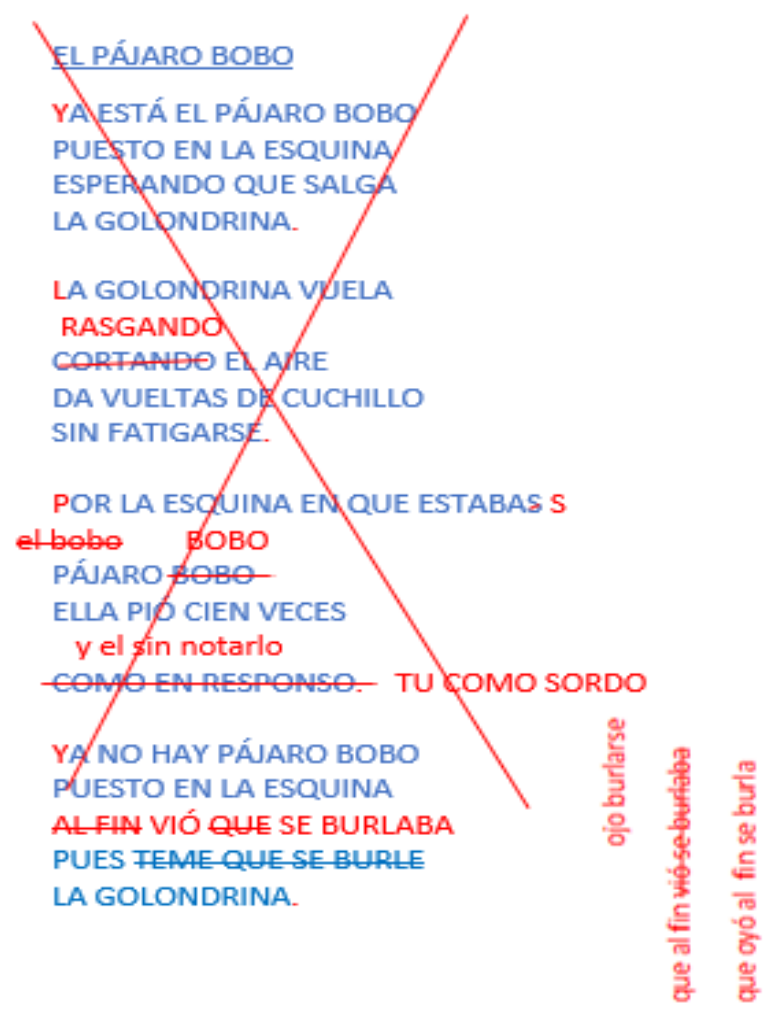

Figura 5. Fondo José Agustín Goytisolo (s. f.: signatura Goy_0218).

La burla expresada en el poema se refuerza si el lector es capaz de evocar la fuente popular que reescribe Goytisolo, una canción de corro infantil de la cual se reúnen distintas versiones procedentes de Extremadura en el Fondo de Música Tradicional del CSIC. Transcribo a continuación la versión que se encuentra en Bonifacio Gil (1931:100): 
Ya está el pájaro bobo

puesto en la esquina

de tené, tenedó,

cara, caracó, tenedó

puesto en la esquina

Después de los versos pares se añade siempre: «de tené, tenedó, cara, caracó, tenedón, repitiéndose el verso a continuación.

esperando que salga

la golondrina.

—-Pues sí, si soy golondrina,

tu ereh muñeca, que cuando vas al baile

te pones güeca.

- Pues si me pongo

güeca,

debo ponerme,

qu'el galán que me ronda,

pesetah tiene.

-Pues si tiene peseta,

que las enseñe,

que te compre un vestido

de seda verde.

-Despuéh del traje

hecho,

que lo eche al fuego,

y veráh qué bien que arde

el vestido nuevo.
XXXI

Ya está el pájaro bobo

puesto en la esquina

esperando que salga

la golondrina

La golondrina que llega

rasgando el aire

da vueltas de cuchillo

sin fatigarse

Por la esquina en que

estabas

pájaro bobo

ella pió cien veces

tú como sordo.

Ya no hay pájaro bobo:

dejó la esquina

sin ver que se burlaba

la golondrina.

Figura 6. Cancionero popular de Extremadura, Bonifacio Gil (1931: 100) y poema de Goytisolo (1980).

El pájaro bobo de Goytisolo es el amante burlado, y la golondrina, la dama altiva que se burla de él en un poema que, a la luz de la canción popular, se interpreta como un baile en el que los personajes se identifican de forma figurada con aves, juego literario que, como hemos señalado, es recurrente en el poemario. 
Por último, también como muestra de la transcendencia de los modelos líricos en la reelaboración que Goytisolo lleva a cabo en los poemas de Los pasos del cazador hasta convertirlos en hitos en el camino del yo poético, se comentan a continuación los cambios en la redacción del poema LXXIII. En este caso, las correcciones permiten observar cómo la canción tradicional o popular no está en la génesis del poema (caso de los textos XXXI y XXXVI), sino que surge en una segunda fase de corrección y de perfeccionamiento de los versos.

\begin{tabular}{|c|c|c|}
\hline & & LXXIII \\
\hline \multicolumn{3}{|l|}{ LA MANTA } \\
\hline \multicolumn{3}{|l|}{ IAYTUMANTA } \\
\hline \multicolumn{2}{|l|}{ LO QUE ME GUSTA MIRARLA! } & lo que me gusta mirarla. \\
\hline \multicolumn{2}{|l|}{ СOMO TU NO ME QUIERAS } & \\
\hline \multicolumn{2}{|l|}{ MI CHICO } & Como tú no decidas \\
\hline \multicolumn{2}{|l|}{ PASAR EN BARCA } & barquero \\
\hline \multicolumn{2}{|l|}{ BAIO ESA MANTA } & pasarme en barca \\
\hline \multicolumn{3}{|l|}{ EL Río } \\
\hline \multicolumn{3}{|l|}{ HORHLA } \\
\hline \multicolumn{2}{|l|}{ ME QUEDARÉ EN ESSUELO } & quedaré en esta orilla \\
\hline MI CHICO & ERPADA & mi chico \\
\hline y BURLADA MIRAN & DEAADA & triste y burlada. \\
\hline RISTE Y HELADA & TRISTE Y $Y A L A D A$ & \\
\hline IAY TU MANTA $\quad$ MIRARLA & & \\
\hline LO QUE ME GUSTA TOCARLAY & & ¡Ay tu barca \\
\hline ¿BARCA! & & lo que me gusta mirarla! \\
\hline
\end{tabular}

Figura 7. Fondo José Agustín Goytisolo (s. f.: signatura Goy_0119) y poema de Goytisolo (1980).

La transformación a la que Goytisolo somete este poema supone convertirlo en una barcarola, de manera que la reescritura permite al poeta incluir en Los pasos del cazador otro subgénero de la lírica tradicional. Frenk (2003: 1511) recoge una muestra de este tipo de composiciones:

Echa acá la barca, ¡hao!
que en el mar de amor me anego.

Se evita además con ello la repetición del motivo de los amores bajo una prenda de abrigo, que ya se trata en el poema LX: 
Tiende el capote ovejero

porque me gusta estar dentro.

El capote

mejor que colchón de lana.

El cielo

mejor que techo en posada.

Y dormir

quédese para mañana.

Tiende el capote ovejero

y vente conmigo adentro.

En este caso, la transformación del poema para introducir el motivo de la barcarola no supone un cambio en los elementos formales del texto, pues se mantiene la estructura de coplas enmarcadas por pareados en las que se reitera un elemento (la manta en la primera versión, la barca en la segunda) que se enfatiza mediante la exclamación, fórmula de carácter tradicional ( iAy tu barca / lo que me gusta mirarla!»).

\section{CONCLUSIONES}

Esta breve incursión en el análisis de las correcciones que José Agustín Goytisolo realizó en los poemas de Los pasos del cazador ha pretendido ser una muestra de cómo la reelaboración de los poemas constituye un proceso, un recorrido, un itinerario, en constante diálogo con las fuentes de la lírica tradicional y de la canción popular de las que pretendió ofrecer un amplio repertorio de subgéneros. La reescritura tuvo como objetivo dotar a cada uno de los textos, de los pasos del poemario de una forma definitiva para lograr la evocación de lo antiguo - los ecos de la lírica tradicional y la canción popular- y su actualización desde la lírica culta.

Las distintas versiones de los tres poemas comentados permiten observar las diversas posibilidades creativas en el proceso de reescritura en relación con las fuentes, temas y motivos de la lírica tradicional: desde la posibilidad de desdibujar la fuente tradicional (poema XXXVI) a mantenerla en todas sus versiones (poema 
XXXI), o la oportunidad de añadir temas y motivos de la canción popular (poema LXXIII).

La lectura de Los pasos del cazador como un itinerario da sentido al poemario entero como un cancionero amoroso del viajero que, al igual que ocurriera con el Arcipreste de Hita en su Libro de Buen Amor, termina transformado por la experiencia. Así se reconoce en los últimos versos de Los pasos del cazador:

\section{LXXXV}

Salió la amapola

en el trigo nuevo:

contempla su luz.

Entre blanco y lila

floreció el ciruelo:

contempla su luz.

Las hojas del chopo

son de un verde fresco:

contempla su luz.

También tú cambiaste

después del invierno:

contempla tu luz.

Futuras investigaciones, en las que pueda valorarse con más detalle el alcance del conjunto de correcciones y de reescrituras que Goytisolo realizó en los textos de Los pasos del cazador (1980), permitirán ahondar en la interpretación de la génesis y de la transformación de estos poemas como hitos, pasos, de un itinerario en el que se muestran y reelaboran distintos subgéneros, temas y motivos recuperados de la lírica popular y reinterpretados en la lírica culta. 


\section{BIBLIOGRAFÍA}

Alonso, Dámaso (1947). «La caza de amor es de altanería (Sobre los precedentes de una poesía de San Juan de la Cruz)», Boletín de la Real Academia Española, 26, pp. 63-79.

Alzueta, Miquel (1981). «La ética caza de José Agustín Goytisolo», El Viejo Topo, octubre, pp. 63-64. Disponible en: https://ddd.uab.cat/pub/jag/jagreccri/1981/GoyP_1725.pdf.

Cotoner, Luisa (2010). «La presencia de la mujer en la poesía

de José Agustín Goytisolo», Lectora, 16, pp. 145-160.

Covarrubias, Sebastián de (1611). Tesoro de la lengua castellana o española, DVD-ROM, ed. Ignacio Arellano y Rafael Zafra, Madrid / Pamplona, Iberoamericana Vervuert / Universidad de Navarra, Studiolum, 2006.

Fondo José Agustín Goytisolo. Universitat Autònoma de Barcelona, Biblioteca d'Humanitats. Disponible en: https://www. bib.uab.cat/human/fonspersonals/goytisolo/fons.php.

Fondo de Música Tradicional IMF-CSIC. A Spanish Collection of Traditional Music Heritage, ed. E. Ros-Fábregas. Disponible en: https://musicatradicional.eu/home.

Frenk, Margit (2003). Nuevo corpus de la antigua lírica popular hispánica (siglos XV a XVII), México, UNAM / El Colegio de México / Fondo de Cultura Económica.

— (2006 [1961]). «Refranes cantados y cantares proverbializados», en Poesía popular hispánica. 44 estudios, México, Fondo de Cultura Económica.

García Mateos, Ramón (1983). «Salamanca en Los pasos del cazador de José Agustín Goytisolo», Revista de Folklore, 3, 28, pp. 131-133.

Gil de Biedma, Jaime (1966). Moralidades, México DF, Joaquín Mortiz.

— (1985). «La imitación como mediación, o de mi Edad Media», en Edad Media y literatura contemporánea, ed. Francisco Rico, Madrid, Trieste.

Gil García, Bonifacio (1931). Cancionero popular de Extremadura,Valls, E. Castells. Góngora, Luis de (2000 [1608]). Romances, ed. Antonio Carreño, Madrid, Cátedra. Goytisolo, José Agustín (1980). Los pasos del cazador, Barcelona, Lumen.

— (1981). A veces gran amor, Barcelona, Laia.

- $\left(2011^{2}\right)$. Poesía completa, ed. Carme Riera y Ramón

García Mateos, Barcelona, Lumen.

Jové, Jordi (2005). «Los pasos del cazador de José Agustín Goytisolo», en Actas del I Simposio Internacional José Agustín Goytisolo, Palma de Mallorca, Universitat de les Illes Balears, pp. 135-138. 
López Castro, Armando (2000). Al vuelo de la garza: estudios sobre Gil Vicente, León, Universidad de León.

Real Academia Española (1726-1739). Diccionario de autoridades. Diccionario de la lengua castellana, en que se explica el verdadero sentido de las voces, su naturaleza y calidad con las phrases o modos de hablar, los proverbios o refranes, y otras cosas convenientes al uso de la lengua, Madrid, Imprenta Francisco del Hierro, 6 vols. Disponible en: http://web.frl.es/DA.html.

— $\left(2014^{23}\right)$. Diccionario de la lengua española, Madrid, Espasa.

Disponible en: https://dle.rae.es/diccionario.

Riera, Carme (1988). La Escuela de Barcelona, Barcelona, Anagrama.

- (1991). Hay veneno y jazmín en tu tinta: aproximación a

la poesía de J. A. Goytisolo, Barcelona, Anthropos.

Roda Bruce, Jaime (1999). «El personaje femenino y las relaciones amorosas en la lírica de tipo tradicional de José Agustín Goytisolo», en Actes del VII Congrés de l'Associació Hispànica de Literatura Medieval, comp. Santiago Fortuño Llorens y Tomàs Martínez Romero, Castelló de La Plana, Universitat Jaume I, pp. 231-244.

Rubio, Fanny (1980). «Cantar y cazar, en los pasos de José

Agustín Goytisolo», El País, 10/VIII/1980.

Torner, Eduardo M. (1966). Lírica hispánica. Relaciones entre lo popular y lo culto, Madrid, Castalia.

Virallonga, Jordi (1992). José Agustín Goytisolo. Vida y obra, Madrid, Libertarias / Prodhufi. Voutsa, Styliani (2012). Contantinos Cavafis y Jaime Gil de Biedma: dos poetas, una concepción vital y estética, Salamanca, Universidad de Salamanca. 